\title{
Effectiveness of the Experimental Fosfatriclaben in Comparison with Two Commercial Fasciolicides in Cattle
}

\section{Tania Rojas-Campos' ${ }^{1}$, Yolanda Vera-Montenegro', ${ }^{1}$ Miguel Flores-Ramos ${ }^{1}$, Rafael Castillo² ${ }^{2}$ Alicia Hernández-Campos ${ }^{2}$, Froylán Ibarra-Velarde ${ }^{{ }^{*}}$}

\author{
${ }^{1}$ Facultad de Medicina Veterinaria y Zootecnia, Departamento de Parasitología, Universidad Nacional Autónoma de México, \\ México City, México \\ ${ }^{2}$ Facultad de Química, Departamento de Farmacia, Universidad Nacional Autónoma de México, México City, México \\ Email: *ibarraf@unam.mx
}

How to cite this paper: Rojas-Campos, T., Vera-Montenegro, Y., Flores-Ramos, M., Castillo, R., Hernández-Campos, A. and IbarraVelarde, F. (2019) Effectiveness of the Experimental Fosfatriclaben in Comparison with Two Commercial Fasciolicides in Cattle. Pharmacology \& Pharmacy, 10, 498-506. https://doi.org/10.4236/pp.2019.1011041

Received: September 5, 2019

Accepted: November 8, 2019

Published: November 11, 2019

Copyright $\odot 2019$ by author(s) and Scientific Research Publishing Inc. This work is licensed under the Creative Commons Attribution International License (CC BY 4.0).

http://creativecommons.org/licenses/by/4.0/

c) (i) Open Access

\begin{abstract}
The aim of the present study was to compare the fasciolicidal efficacy in cattle of an experimental water-soluble compound, named fosfatriclaben, a prodrug of triclabendazole, with two commercial fasciolicides. For this, twenty-four cross mixed milking cows, aged between 1 to 3 years, naturally infected with Fasciola hepatica, were used. To apply the treatment, animals were divided into 4 groups of 6 animals each being ranked according to their fecal flukeegg count from the highest to the lowest number of eggs. The compounds were administered in the groups with a single dose. Group 1 (G1) was treated with $6 \mathrm{mg} / \mathrm{kg} / \mathrm{IM}$ of fosfatriclaben, G2 was treated with triclabendazole at 12 $\mathrm{mg} / \mathrm{kg} / \mathrm{PO}$; G3 was treated with $5 \%$ closantel at $10 \mathrm{mg} / \mathrm{kg} / \mathrm{SC}$ and G4 was administered with $5 \mathrm{~mL} / \mathrm{IM}$ of deionized water and served as untreated control. Fecal samples were analyzed on days- $-8,0$ (treatment day), 7, 14, 21 and 28 to count the number of fasciola eggs before and after the treatment using the sedimentation test. The efficacy was assessed as the percentage of fluke-egg reduction on treated groups relative to the untreated control. The resulting data were analyzed by the Kruskal-Wallis non-parametric test, using the statistical IBM SPSS 24.0 (2016) program. Results indicated a fluke-egg reduction of $100 \%$ for fosfatriclaben along the study; triclabendazole showed an efficacy of $99.7 \%-100 \%$ from day 7 to day 28 . In the case of closantel, values from $98.8 \%$ to $99.6 \%$ were recorded from day 7 to day 28 . No statistical differences between treatments were observed $(\mathrm{P}<0.05)$. It was concluded that the experimental fosfatriclaben administered at $6 \mathrm{mg} / \mathrm{kg} / \mathrm{IM}$ to naturally infected cattle exerted a fasciolicidal efficacy similar to the drugs of choice for the treatment of fasciolosis (triclabendazole) when administered at $12 \mathrm{mg} / \mathrm{kg} /$ $\mathrm{PO}$, and closantel injected at $10 \mathrm{mg} / \mathrm{kg} / \mathrm{SC}$.
\end{abstract}




\section{Keywords}

Fasciola hepatica, Prodrug, Triclabendazole, Closantel, Cattle

\section{Introduction}

Fasciolosis is a zoonotic parasitic disease of worldwide distribution [1] caused by the liver fluke Fasciola hepatica which affects different kind of animals [2]. Its relevance relies in huge economic losses in cattle production [3] [4]. Among different drugs used to treat this disease, triclabendazole has shown high efficacy against young and adult stages with a wide margin of safety when applied by the oral route [5] [6]. Closantel is also a fasciolicide of choice; in addition, it also kills nematodes such as Haemonchus contortus, and the fly Oestrus ovis [7] [8].

Recently our research group has synthesized a new water-soluble triclabendazole prodrug, named fosfatriclaben. This new compound increased the aqueous solubility 88,000 -fold with respect to its precursor compound (triclabendazole) and allowed the formation of an aqueous solution for IM administration [9] (Figure 1).

In this work, we present the fasciolicidal efficacy of the fosfatriclaben compared with two commercials well known fasciolicides in naturally infested cattle.

\section{Material and Methods}

\subsection{Study Location}

The present study was carried out during the month of march, 2019, in a farm named "Mi Alma" located at approximately $150 \mathrm{~km}$ from Mexico City.

\subsection{Experimental Animals}

Twenty-four cross mixed adult bovines, both sexes, aged between 1 to 3 years, naturally infected with Fasciola hepatica were used. Food was provided as a balanced feed containing oats, alfalfa and ensilage. Water was available ad libitum.

The animals were previously selected on day 8 as positive to fasciola-eggs<smiles>CSc1nc2cc(Oc3cccc(Cl)c3Cl)c(Cl)cc2[nH]1</smiles>

Triclabendazole<smiles>Cc1nc2cc(Oc3cccc(Cl)c3Cl)c(Cl)cc2n1COP(=O)([O-])[O-]</smiles>

Fosfatriclaben

Figure 1. Structure of triclabendazole and fosfatriclaben. 
using the traditional sedimentation test [10]. Shortly, feces were collected directly from the rectum and thoroughly homogenized to place $5 \mathrm{~g}$ in a glass using tap water. The mixture was placed in a beaker and sifted with the aid of a plastic sieve. After $10 \mathrm{~min}$ repose, the supernatant was decanted and fulfilled again with tap water. The process was repeated until the sediment was observed clean. The final sediment was observed under stereoscopic microscope to carry out the fluke-egg counting [10].

The animals were identified by ear tag.

\subsection{Conduction of the Study}

To apply the treatment, animals were divided into 4 groups of 6 animals each being ranked according to their fecal-egg count from the highest to the lowest number of eggs.

Group 1 (G1) was treated with $6 \mathrm{mg} / \mathrm{kg}$ of the experimental water-soluble fosfatriclaben injected once by the IM route. G2 was treated with triclabendazole (Fasimec ${ }^{\circledR}$ Elanco Australasia) given once at $12 \mathrm{mg} / \mathrm{kg} / \mathrm{PO}$; G3 was treated with $5 \%$ closantel $^{\circledR}$ (Closantil-Chinoin) at $10 \mathrm{mg} / \mathrm{kg} / \mathrm{SC}$ and $\mathrm{G} 4$ was the control group and it was injected with $5 \mathrm{~mL}$ of deionized water.

Fecal samples were analyzed by the sedimentation test [10], on days $-8,0$ (day of treatment), 7, 14, 21 and 28 to count the number of eggs present in each one of the experimental animals, following the guide for evaluation of anthelmintics suggested by the World Association for Advancement of Veterinary Parasitology (WAAVP) [11] [12].

\subsection{Assessment of Efficacy}

The efficacy was calculated as the percentage of fluke-egg reduction on the treated groups, relative to the untreated control, according to the following formula [11].

Efficacy $=\frac{\text { Arithmetic mean number of fluke eggs }(\text { Control })-\text { Arithmetic mean number of fluke eggs }(\text { Treated })}{\text { Arithmetic mean number of fluke eggs }(\text { Control })} \times 100$

\subsection{Statistical Analysis}

The obtained data were compared between the experimental groups using the non-parametric Kruskal-Wallis test. They were analyzed with the statistical IBM SPSS 24.0 (2016) software [13].

\section{Results and Discussion}

Table 1 shows the coprological analyses in which the total and mean number of fluke-eggs, observed in the experimental groups.

The percentage of efficacy exerted by fosfatriclaben, triclabendazole and closantel, at 7, 14, 21 and 28 days post-treatment is shown in Figure 2. Fosfatriclaben showed $100 \%$ reduction of eggs from day 7 to day 28 ; triclabendazole dosed orally showed an efficacy of $99.7 \%$ at day 7 , and $100 \%$ from day 14 to day 28 . 
Table 1. Percentage of fluke-egg reduction before and after treatment with fosfatriclaben compared with two commercial fasciolicides in cattle naturally infected with Fasciola hepatica.

\begin{tabular}{|c|c|c|c|c|c|c|c|c|}
\hline \multirow{2}{*}{$\begin{array}{l}\text { Group } \\
(n=6)\end{array}$} & \multirow{2}{*}{$\begin{array}{l}\text { Compound and route } \\
\text { of administration }\end{array}$} & \multirow{2}{*}{$\begin{array}{l}\text { Dose rate } \\
(\mathrm{mg} / \mathrm{Kg})\end{array}$} & \multicolumn{6}{|c|}{ Days of fecal sampling } \\
\hline & & & -8 & $0^{*}$ & 7 & 14 & 21 & 28 \\
\hline \multirow[t]{8}{*}{1} & Fosfatriclaben & 6 & 347 & 346 & 0 & 0 & 0 & 0 \\
\hline & & & 100 & 93 & 0 & 0 & 0 & 0 \\
\hline & & & 72 & 290 & 0 & 0 & 0 & 0 \\
\hline & & & 23 & 32 & 0 & 0 & 0 & 0 \\
\hline & & & 13 & 21 & 0 & 0 & 0 & 0 \\
\hline & & & 14 & 17 & 0 & 0 & 0 & 0 \\
\hline & Average & & 94.83 & 133.17 & 0 & 0 & 0 & 0 \\
\hline & Efficacy (\%) & & & & 100 & 100 & 100 & 100 \\
\hline \multirow[t]{8}{*}{2} & Triclabendazole & 12 & 300 & 306 & 0 & 0 & 0 & 0 \\
\hline & & & 137 & 130 & 2 & 0 & 0 & 0 \\
\hline & & & 67 & 69 & 1 & 0 & 0 & 0 \\
\hline & & & 23 & 125 & 0 & 0 & 0 & 0 \\
\hline & & & 13 & 13 & 0 & 0 & 0 & 0 \\
\hline & & & 13 & 19 & 0 & 0 & 0 & 0 \\
\hline & Average & & 92.16 & 110.33 & 0.5 & 0 & 0 & 0 \\
\hline & Efficacy (\%) & & & & 99.7 & 100 & 100 & 100 \\
\hline \multirow[t]{8}{*}{3} & Closantel & 10 & 212 & 730 & 0 & 0 & 0 & 0 \\
\hline & (SC) & & 170 & 167 & 0 & 0 & 0 & 0 \\
\hline & & & 58 & 266 & 0 & 0 & 0 & 0 \\
\hline & & & 30 & 33 & 0 & 0 & 0 & 0 \\
\hline & & & 89 & 110 & 15 & 8 & 5 & 7 \\
\hline & & & 14 & 15 & 0 & 0 & 0 & 0 \\
\hline & Average & & 95.5 & 220.17 & 2.5 & 1.33 & 0.83 & 1.33 \\
\hline & Efficacy (\%) & & & & 98.8 & 99.5 & 99.7 & 99.5 \\
\hline \multirow[t]{7}{*}{4} & Control group & untreated & 373 & 383 & 432 & 436 & 442 & 462 \\
\hline & & & 89 & 161 & 601 & 778 & 761 & 760 \\
\hline & & & 78 & 76 & 187 & 180 & 188 & 192 \\
\hline & & & 21 & 57 & 54 & 135 & 128 & 125 \\
\hline & & & 15 & 42 & 40 & 54 & 56 & 56 \\
\hline & & & 21 & 17 & 18 & 56 & 55 & 60 \\
\hline & Average & & 99.5 & 122.66 & 222 & 273.16 & 271.66 & 275.83 \\
\hline
\end{tabular}

*day of treatment. 


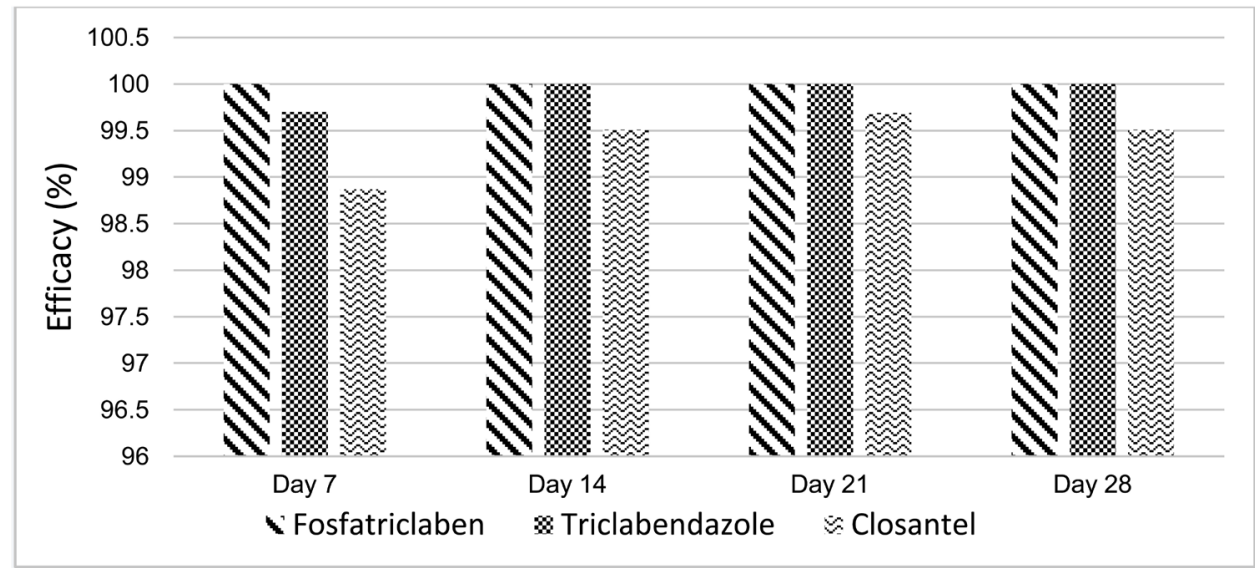

Figure 2. Percentage of efficacy of fosfatriclaben compared with two fasciolicides in the experimental groups.

Finally, closantel showed values between $98.8 \%$ and $99.7 \%$ in the study. No significant differences were observed when the experimental treated groups were compared $(\mathrm{P}<0.05)$.

It is well known that an experimental compound should have high solubility, suitable chemical stability and neutral $\mathrm{pH}$ to be adequate for intramuscular application [14]. This could be of great value in veterinary medicine, since it is common to prefer the parenteral treatment application considering the different advantages such as easy of treatment, decreasing stress of the animals, decreasing danger to the operator, the bioavailability of the drug is faster than oraldosing products. In fact, it is a good advantage since the drug applied intramuscularly reaches the site of action without passing by the gastrointestinal barriers which may affect the drug bioavailability [15] [16].

Another important point is that the injectable drugs require less active ingredient to provoke a clinical effect and therefore less quantity of compound [15].

It is important to know that fosfatriclaben uses only half of the dose $(6 \mathrm{mg} / \mathrm{kg} /$ IM) to achieve $100 \%$ egg reduction, in comparison with its precursor triclabendazole $(12 \mathrm{mg} / \mathrm{kg} / \mathrm{PO})$. This can be considered relevant since the environment could be less contaminated.

In 2014, [14] described the synthesis of a benzimidazole derivative named alfa-pro the compound being highly soluble in water. This compound was initially tested under in vitro conditions rendering $100 \%$ efficacy against newly excysted flukes. Afterwards, the authors tested the compound in artificially infected sheep at a dose of $4 \mathrm{mg} / \mathrm{kg} / \mathrm{IM}$ removing $87.8 \%$ of flukes. Recently, [17] determined the effective dose of the alfa-pro against immature and adult Fasciola hepatica in experimentally infected sheep. This benzimidazole soluble drug cleared $97.6 \%, 98.5 \%$ and $98.8 \%$ of adult flukes when administered at 6,8 and 10 $\mathrm{mg} / \mathrm{kg} / \mathrm{IM}$, respectively, and $81.2 \%$ at $6 \mathrm{mg} / \mathrm{kg} / \mathrm{IM}$ against 5 -week-old flukes.

Considering that nowadays the bioavailability of benzimidazoles have increased tremendously, and been aware of the great potential of triclabendazole as fasciolicide, it was decided to create the new fosfatriclaben for parenteral use ex- 
pecting to obtain similar efficacy to its oral precursor (triclabendazol) with the advantage of using half of the dose required to remove adult and juvenile flukes.

Wood et al. [11] mentioned that studies like this in which the fluke-egg reduction is evaluated, give valuable information in cattle, even when the number of adult flukes removed is unknown. Unfortunately, critical tests in cattle involving sacrifice are very expensive to run, therefore the alternative to assess egg-reduction in cattle is widely accepted and considered of a great value.

On the other hand, no significant differences were observed between treatments $(P<0.05)$, indicating that possibly fosfatriclaben, applied once by the intramuscular route to cattle is as effective as its precursor triclabendazole (PO), recognized to date as the most effective and safer fasciolicidal agent. However, is important to note that not in all cases triclabendazole has removed $100 \%$ of flukes, perhaps this is in part because of the appearance of resistance to this drug in different parts of the world [6] [18] [19] [20].

It is important to emphasize that none of the other commercial fasciolicides tested were able to remove fluke eggs at $100 \%$ along period of the experiment.

Different studies have demonstrated the high fasciolicidal efficacy exerted by closantel [21]. However, this drug only exerts high efficacy to flukes older than 6 weeks of age. Certainly, this confer the probability to the remaining flukes after treatment could be continue maturing to produce more eggs.

In coincidence with data obtained by [22] who treated 41 cows with closantel at $5 \mathrm{mg} / \mathrm{kg} / \mathrm{SC}$; then, they found fluke-eggs 3 weeks after the treatment.

In addition, [23] observed fluke-eggs after treatment with closantel, obtaining $72 \%$ and $92 \%$ of efficacy. Nevertheless, closantel is still being well recognized as a good fasciolicide and it also shows good efficacy against other parasites such as Haemonchus contortus and Oestrus ovis.

In contrast to this situation, fosfatriclaben at present reaches up to $100 \%$ efficacy since as a new experimental drug is used in a very limited manner.

Results obtained in this study suggest that the experimental fosfatriclaben is a good candidate to be consider for the treatment of fasciolosis in cattle. Further studies will determine the real potential of this experimental drug indicated for parenteral use in sheep and cattle.

At present, this drug is under different biological tests aimed to know the mode of action, drug stability as well as the withholding period. This compound is patented by the Mexican Institute for Industrial Protection (Instituto Mexicano de la Protección Industrial) (MX2014014417A) and it also obtained the patent of USA (US10239842 B2).

\section{Conclusion}

The experimental fosfatriclaben, a highly water-soluble prodrug, administered at $6 \mathrm{mg} / \mathrm{kg} / \mathrm{IM}$ to naturally infected cattle exerted similar fasciolicidal efficacy to its precursor triclabendazole when it is dosed at $12 \mathrm{mg} / \mathrm{kg} / \mathrm{PO}$, and closantel injected at $10 \mathrm{mg} / \mathrm{kg} / \mathrm{SC}$. 


\section{Acknowledgements}

This work was supported by UNAM-PAPIIT-IT201018. M. Flores-Ramos is very grateful to Dirección General de Asuntos del Personal Académico (DGAPA, UNAM) for the Postdoctoral fellowship granted. The authors are indebted to Laboratorios Loeffler for kind donation of triclabendazole. The authors are grateful to the owners of the farm "Mi Alma", for permission to use their cattle.

\section{Availability of Data and Material}

All datasets are included in this manuscript.

\section{Funding}

The present study was carried out thanks to the project PAPIIT-DEGPA-UNAM No. RT201018.

\section{Contributors}

MFR, RC, AHC contributed with the synthesis of the fosfatriclaben, manuscript revision and discussion. All other authors contributed to the study design, carried out the field study, performed laboratory analysis, collaborated with results interpretation, data analysis, manuscript revision and discussion: Performed statistical data analysis and suggested the experimental design: FIV, YVM, and Wrote the paper: FIV with input from YVM Grant funding: FIV. All authors supervised the experimental procedures, read and approved the final version of the manuscript.

\section{Animal Research}

The work was carried out adhering to the guidelines of the Institutional Committee for Use and Care of Experimental Animals of the institution, according to the Mexican Official Regulation NOM-062-ZOO-1999 and Animal Research: Reporting of In Vivo Experiments guidelines was followed.

\section{Conflicts of Interest}

The authors declare no conflicts of interest regarding the publication of this paper.

\section{References}

[1] Soliman, F.M. (2008) Epidemiological Review of Human and Animal Fascioliasis in Egypt. Journal of Infect Developing Countries, 2, 182-189. https://doi.org/10.3855/jidc.260 https://www.ncbi.nlm.nih.gov/pubmed/19738348

[2] Gil, L.C., Díaz, A., Rueda, C., Martínez, C., Castillo, D. and Apt, W. (2014) Fascioliasis hepática humana: Resistencia al tratamiento con triclabendazol. Revista Médica de Chile, 142, 1330-1333. https://doi.org/10.4067/S0034-98872014001000014

[3] Bennett, R., Christiansen, K. and Hadley, R. (1999) Preliminary Estimates of the Direct Cost Associated with Endemic Diseases of Livestock in Great Britain. Pre- 
ventive Veterinary Medicine, 39, 155-171.

https://doi.org/10.1016/S0167-5877(99)00003-3

https://www.ncbi.nlm.nih.gov/pubmed/10327436

[4] Kaplan, R.M. (2002) Fasciola hepatica: A Review of the Economic Impact in Cattle and Considerations for Control. Veterinary Therapeutics, 2, 40-50.

https://www.ncbi.nlm.nih.gov/pubmed/19753697

[5] Boray, J.C., Crowfoot, P.D., Strong, M.B., Allison, J.R., Schellenbaum, M., Von Orelli M. and Sarasin, G. (1983) Treatment of Immature and Mature Fasciola hepatica Infections in Sheep with Triclabendazole. Veterinary Record, 113, 315-317. https://doi.org/10.1136/vr.113.14.315 https://www.ncbi.nlm.nih.gov/pubmed/6649348

[6] Ibarra, V.F., Montenegro, C.N., Vera, M.Y., Castillo, B.R., Hernández, C.A. and Ochoa, G.P. (2002) Comparative Efficacy of an Experimental Fasciolicide, Triclabendazole and Closantel in Cattle Naturally Infected with Fasciola hepatica. Veterinaria México, 33, 237-245.

https://www.medigraphic.com/pdfs/vetmex/vm-2002/vm023c.pdf

[7] Rothwell, J. and Sangster, N. (1997) Haemonchus contortus: The Uptake and Metabolism of Closantel. International Journal of Parasitology, 27, 313-319. https://doi.org/10.1016/S0020-7519(96)00200-7

[8] Matos, V., Rodríguez, D., Alfonso, P., Martín, J., Mengana, E., Pérez, E., Moya, S. and Matos, K. (2011) Antiparasitic Efficacy of Ivermectin and Closantel in Naturally oestrus ovis Infested Sheeps. Revista de Salud Animal, 33, 184-189.

http://scielo.sld.cu/scielo.php?script=sci_arttext\&pid=S0253-570X2011000300007\&l $\underline{\text { ng=es\&tlng=es }}$

[9] Flores-Ramos, M., Ibarra-Velarde, F., Jung-Cook, H., Hernández-Campos, A., Vera-Montenegro, Y. and Castillo, R. (2017) Novel Triclabendazole Prodrug: A Highly Water Soluble Alternative for the Treatment of Fasciolosis. Bioorganic \& Medicinal Chemistry Letters, 27, 616-619. https://doi.org/10.1016/j.bmcl.2016.12.004

[10] Rodríguez, V.R., Galera, C. and Amira, L. (2015) Técnicas diagnósticas en Parasitología Veterinaria. 2da Edición, Universidad Autónoma de Yucatán, Mérida, México.

[11] Wood, I.B., Amaral, N.K., Bairden, K., Duncan, J.L., Kassai, T. and Malone, J.B. (1995) World Association for the Advancement of Veterinary Parasitology (WAAVP) Second Edition of Guidelines for Evaluating the Efficacy of Anthelmintics in $\mathrm{Ru}$ minants (Bovine, Ovine, Caprine). Veterinary Parasitology, 58, 181-213.

https://doi.org/10.1016/0304-4017(95)00806-2

https://www.ncbi.nlm.nih.gov/pubmed/7571325

[12] Marchiondo, A.A., Holdsworth, P.A., Fourie, L.J., Rugg, D., Hellmann, K., Snyder, D.E. and Dryden, M.W. (2013) World Association for the Advancement of Veterinary Parasitology (W.A.A.V.P.) Second Edition: Guidelines for Evaluating the Efficacy of Parasiticides for the Treatment, Prevention and Control of Flea and Tick Infestations on Dogs and Cats. Veterinary Parasitology, 194, 84-97.

https://doi.org/10.1016/j.vetpar.2013.02.003 https://www.ncbi.nlm.nih.gov/pubmed/23741753

[13] IBM Corp (2016) IBM SPSS Statistics Para Windows, Version 24.0. IBM Corp, Armonk, NY.

[14] Flores, R.M., Ibarra, V.F., Hernández, C.A., Vera, M.Y., Jung, C.H., Cantó, A.G.J., Del Rivero, L.M. and Castillo, R. (2014) A Highly Water Soluble Benzimidazole De- 
rivative Useful for the Treatment of Fasciolosis. Bioorganic and Medicinal Chemistry Letters, 24, 5814-5817. https://doi.org/10.1016/j.bmcl.2014.10.017 https://www.ncbi.nlm.nih.gov/pubmed/25455496

[15] Spahn, J.D. and Szefler S.J. (2008) Chapter 16, Pharmacology of the Lung and Drug Therapy. In: Taussig, L.M. and Landau, L.I., Eds., Pediatric Respiratory Medicine, 2nd Edition, Elsevier B.V., Amsterdam, 219-233. https://doi.org/10.1016/B978-032304048-8.50020-7

[16] Sumano, L., Ocampo, C. and Gutiérrez, O. (2015) Farmacología Veterinaria. Mc Graw Hill, New York.

[17] Ibarra, F., Vera, Y., Quiroz, H., Cantó, J., Castillo, R., Hernández, A. and Ochoa, P. (2018) Determination of the Effective Dose of an Experimental Fasciolicide in Naturally and Experimentally Infected Cattle. Veterinary Parasitology, 120, 65-74. https://doi.org/10.1016/j.vetpar.2003.12.005 https://www.ncbi.nlm.nih.gov/pubmed/15019144

[18] Romero, J., Villaguala, C., Quiroz, F., Landaeta-Aqueveque, C., Alfaro, G. and Pérez, R. (2019) Flukicide Efficacy against Fasciola hepatica of Triclabendazole and Nitroxynil in Cattle of the Central Valley of Chile. Revista Brasileira de Parasitología Veterinaria, 28, 164-167. https://doi.org/10.1590/s1984-296120180089 https://www.ncbi.nlm.nih.gov/pubmed/30892461

[19] Stevenson, C.R., Mahoney, R.H., Fisara, P., Strehlau, G. and Reichel, M.P. (2002) The Efficacy of Formulations of Triclabendazole and Ivermectin in Combination against Liver Fluke (Fasciola hepatica) and Gastro-Intestinal Nematodes in Cattle and Sheep and Sucking Lice Species in Cattle. Australian Veterinary Journal, 80, 698-701. https://doi.org/10.1111/j.1751-0813.2002.tb11303.x https://www.ncbi.nlm.nih.gov/pubmed/12465830

[20] Vera, M.Y., Ibarra, V.F., Quiroz, R.H., Hernández, C.A. and Castillo, R. (2003) Field Trial on the Efficacy of an Experimental Fasciolicide Compared with Some Commercial Compounds in Naturally Infected Cattle. Parasitology Research, 91, 1-4. https://doi.org/10.1007/s00436-003-0901-y https://www.ncbi.nlm.nih.gov/pubmed/12844256

[21] Fairweather, I. and Boray, J.C. (1999) Fasciolicides: Efficacy, Actions, Resistance and Its Management. Veterinary Journal, 158, 81-112.

https://doi.org/10.1053/tvjl.1999.0377 https://www.ncbi.nlm.nih.gov/pubmed/10489266

[22] Shin, S.S., Lee, C.G., Cho, S.H., Kim, J.T. and Wee, S.H. (1995) Efficacy of Closantel for the Treatment of Naturally-Acquired and Experimentally Induced Fasciola hepatica Infections in Cattle. Korean Journal of Veterinary Research, 35, 347-352. http://www.koreascience.or.kr/article/JAKO199524457071152.page

[23] Novobilský, A. and Höglund, J. (2015) First report of Closantel Treatment Failure against Fasciola hepatica in Cattle. International Journal for Parasitology: Drugs and Drug Resistance, 5, 172-177. https://doi.org/10.1016/j.ijpddr.2015.07.003 https://www.ncbi.nlm.nih.gov/pubmed/26448903 